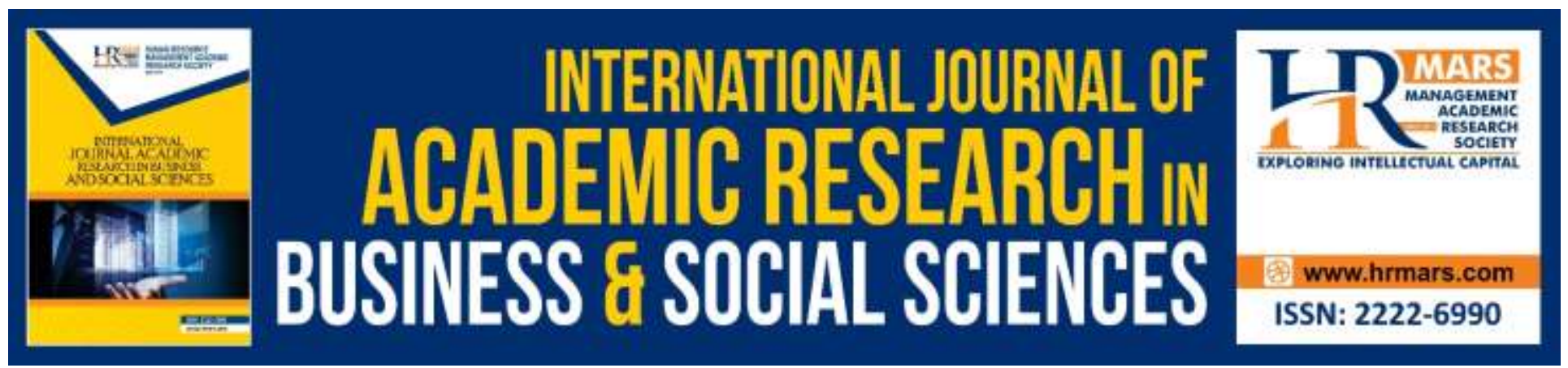

\title{
Factors Affecting Levels of Acceptance of Academicians in Using Blended Learning (BL) System in Teaching by Using Extended Model of UTAUT
}

\author{
Nor Aslily Sarkam
}

To Link this Article: http://dx.doi.org/10.6007/IJARBSS/v9-i13/6510

DOI: $10.6007 /$ IJARBSS/v9-i13/6510

Received: 08 August 2019, Revised: 19 August 2019, Accepted: 03 September 2019

Published Online: 30 September 2019

In-Text Citation: (Sarkam, 2019)

To Cite this Article: Sarkam, N. A. (2019). Factors Affecting Levels of Acceptance of Academicians in Using Blended Learning (BL) System in Teaching by Using Extended Model of UTAUT. International Journal of Academic Research in Business and Social Sciences, 9(13), 329-339.

Copyright: (C) 2019 The Author(s)

Published by Human Resource Management Academic Research Society (www.hrmars.com)

This article is published under the Creative Commons Attribution (CC BY 4.0) license. Anyone may reproduce, distribute, translate and create derivative works of this article (for both commercial and non-commercial purposes), subject to full attribution to the original publication and authors. The full terms of this license may be seen at: http://creativecommons.org/licences/by/4.0/legalcode

Special Issue: Revolutionizing Education: Challenges, Innovation, Collaboration, 2019, Pg. 329 - 339 http://hrmars.com/index.php/pages/detail/IJARBSS JOURNAL HOMEPAGE

Full Terms \& Conditions of access and use can be found at http://hrmars.com/index.php/pages/detail/publication-ethics 


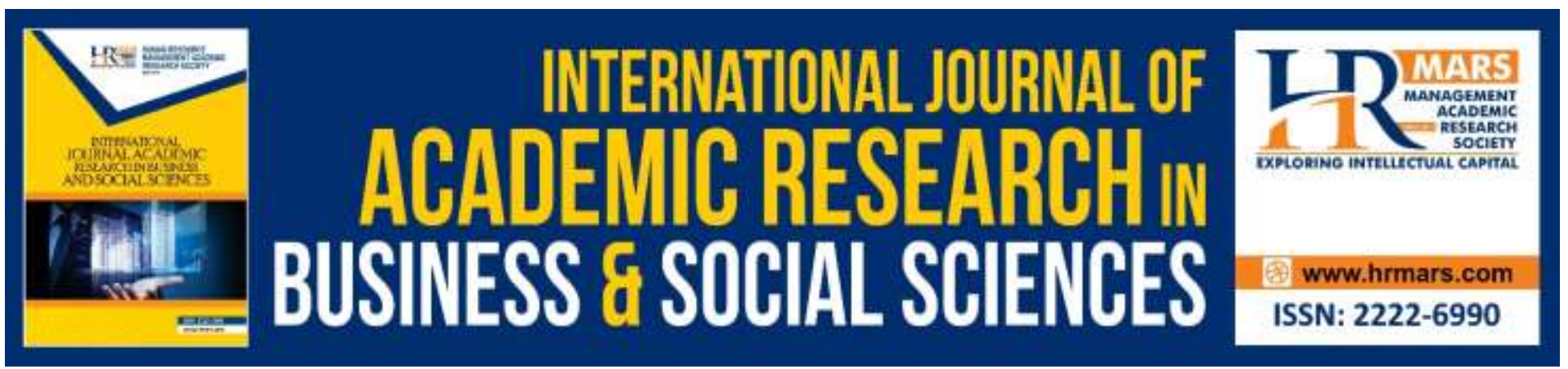

\title{
Factors Affecting Levels of Acceptance of Academicians in Using Blended Learning (BL) System in Teaching by Using Extended Model of UTAUT
}

\author{
Nor Aslily Sarkam
}

Graduate School of Economics and Management,Tohoku University, Sendai, Japan

\begin{abstract}
Nowadays, the development of information and communication technology (ICT) has greatly influenced academician's way of communication with student. Thus, its enhanced student's understanding inside and outside of the classroom. Realizing this, the blended learning (BL) system in teaching is implemented in most institutions all over the world including Malaysia. Due to the wide spread implementations of the BL system in teaching, academicians need to adapt their teaching in order to utilize it. Despite the efforts in motivating academicians to use the BL system in teaching, there are mixed feelings by the academicians whether to accept and use or reject completely this system. In this study, the Unified Theory of Acceptance and Use of Technology (UTAUT) model including new constructs for explaining the level of acceptance using the BL system in teaching is investigated. The two new constructs in UTAUT are perceived usefulness and attitude. And two new moderator variables which are user type and teaching experience is added. The results show that performance expectancy has an impact on the behavior intention while facilitating conditions has a significant effect on actual usage behavior for user type and teaching experience groups. The findings suggest that lecturers with more than 5 years of experiences have the highest level of acceptance in accepting the BL system in teaching.
\end{abstract}

Keywords: Attitude, Blended Learning, Moderation, Perceived Playfulness, UTAUT

\section{Introduction}

The implementation of information and communication technology (ICTs) in teaching and learning activities has attracted considerable attentions among academicians all over the world (Jones et al., 2008; Gawande, 2014). Today, many schools and universities have started to adopt and implement ICT solutions in both inside and outside of classroom that enable flexibility in teaching and in the learning process that reinforce interactivity in the learning environment. Thus, the interest in ICT has attracted many researchers to draw substantial research attention. Utilization of wikis, blog, discussion forums, electronic mails (Gawande, 2015) in learning and teaching in schools and 
universities can highly change existing curriculum designs, and more importantly, e-learning has become the significant part of the teaching and learning experience among academicians and students (Radcliffe, 2002; Gawande, 2015). Compared to e-learning, many authors such as Gawande (2015) and Norberg et al., (2011) have predicted that the concept of blended learning (BL) system in teaching which defined as the combination of traditional learning and technology-mediated instructions would be a new model in coming era in schools and universities courses.

However, the concept of BL system in teaching is still an ambiguity in terms of its conceptual definition even though the system offers many benefits to teachers, lecturers, and students alike. For instance, based on previous studies that have been compared to traditional learning, BL system in teaching provides greater flexibility, good communication, motivation, self-learning, learning fun, and idea sharing (Haron et al., 2012; Osman \& Hamzah, 2016; Hubackova et al., 2011; Gawande, 2015). These studies have been conducted by various countries who have concluded that BL system in teaching that utilized online education is an important component of the long-term strategy. As such, the implementation and awareness of BL system in teaching is important.

In the past a study by Haron et al., (2012) which are focusing on academicians in Malaysia, shows the results are still inconsistent where only 13 percent of academicians are implementing $\mathrm{BL}$ system in teaching. Although, the studies in other countries (Hubackova et al., 2011; Gawande, 2015) shows significant results in the implementations of BL system in teaching, Malaysian academicians seem not aware of the findings. Thus, further investigations towards Malaysian academician's acceptance of BL system in teaching is crucial.

In a study by Wong et al., (2012) has stated that the instructor's acceptance on the use of BL system in teaching and learning lie with the problem of Internet access. In another study by Ross and Seymour (1999), they mentioned that most of the attitudes held by the academicians towards implementation of BL in teaching were primarily negative because the participants doubt the quality of the education that students can receive through online courses. Other studies have reached similar conclusions about attitudes toward online courses (Appana, 2008; Barker, 2003; Mancuso-Murphy, 2007; Mclsaac, 2003). Therefore, to understand the level of acceptance among academicians towards $\mathrm{BL}$ system in teaching, it is interesting to analyze the influence of the game and enjoy which reflect on the attitudes of the academicians and students. And due to the contradictory results by Wang et al. (2012); Ross and Seymour (1999), it is necessary to analyze in detail what are the determinants of intention to use the additional constructs and moderating variables. Thus, the objectives of this study are two folds. First, to test the UTAUT extended model including perceived playfulness and attitude as intrinsic motivator for explaining the level of acceptance to use BL system in teaching. Second, to analyze the differences in the model related to gender, age, user type, and teaching experience.

\section{Theoretical Development and Research Hypotheses}

In this study, UTAUT is chosen as a ground theory for developing the technology acceptance research model in investigating the level of acceptance among academicians on BL system in teaching, especially in the learning technology field. The base UTAUT model has been extended with perceived playfulness (PP) and attitude (ATT) through the use of technology and is refer as extended UTAUT model. The perceived playfulness (PP) and attitude (ATT) towards using technology were added because several studies (Venkatesh et al.,2003; Durndell and Thomson, 1997) have shown a significant relationship between both variables with behavior intention (BI) and usage behavior (UB). 
To analyze the differences in causal relationships between UTAUT construct with moderating variables. Based on the objectives stated, the following hypothesis is proposed:

H1: Perceived Expectancy (PE) has a positive and significant effect on the behavior intention (BI).

$\mathrm{H} 1 \mathrm{a}$ : The influence of performance expectancy $(\mathrm{PE})$ on the behavior intention (BI) will be moderated by gender and age.

$\mathrm{H} 1 \mathrm{~b}$ : The influence of performance expectancy (PE) on the behavior intention (BI) will be moderated by user type and teaching experience.

$\mathrm{H}$ 2: Effort expectancy (EE) has a positive and significance effect on the behavior intention (BI).

$\mathrm{H} 2 \mathrm{a}$ : The influence of effort expectancy (EE) on the behavior intention (BI) will be moderated by gender and age.

$\mathrm{H} 2 \mathrm{~b}$ : The influence of effort expectancy (EE) on the behavior intention (BI) will be moderated by user type and teaching experience.

$\mathrm{H} 3$ : Social influence (SI) has a positive and significant effect on the behavior intention (BI).

$\mathrm{H3a}$ : The influence of social influence (SI) on the behavior intention ( $\mathrm{BI}$ ) will be moderated by gender and age.

$\mathrm{H} 3 \mathrm{~b}$ : The influence of social influence ( $\mathrm{SI}$ ) on the behavior intention (BI) will be moderated by user type and teaching experience.

H4: Perceived playfulness (PP) has a positive and significance effect on the BI.

$\mathrm{H} 4 \mathrm{a}$ : The influence of perceived playfulness (PP) on the behavior intention (BI) will be moderated by gender and age.

$\mathrm{H} 4 \mathrm{~b}$ : The influence of perceived playfulness (PP) on the behavior intention (BI) will be moderated by user type and teaching experience.

$\mathrm{H} 5$ : Facilitating conditions ( $\mathrm{FC}$ ) has a positive and significant effect on the behavior intention (BI).

$\mathrm{H} 5 \mathrm{a}$ : The influence of facilitating conditions $(\mathrm{FC})$ on the behavior intention (BI) will be moderated by user type and teaching experience.

H6: Behavior intention (BI) has a positive and significant effect on the usage behavior (UB).

H7: Performance expectancy (PE) has a positive and significant effect on attitude (ATT).

H8: Effort expectancy (EE) has a positive and significant effect on attitude (ATT).

H9: Attitude (ATT) has a positive and significant effect on the usage behavior (UB) of BL.

\section{Result and Discussion \\ Reliability and Validity}

The measurement items in the questionnaire were first assessed for convergent and discriminant validity, as well as for reliability before, proceeding to test the hypotheses. Venkatesh et al., (2003) suggests the reliability used to ensure the content of validity in the measurement items. Table 1 summarizes the results of internal reliability, which has been assessed by estimating Cronbach's alpha. In this study, the Cronbach's alpha is set at 0.60 as suggests by Nunnally (1978) and commonly practice in the existing studies of Kline (1998); Zainudin (2015); Kim and Park (2013). Thus, all the indicators remain in the measurement model. 
INTERNATIONAL JOURNAL OF ACADEMIC RESEARCH IN BUSINESS AND SOCIAL SCIENCES

Vol. 9, No. 13, Special Issue: Revolutionizing Education: Challenges, Innovation, Collaboration., 2019, E-ISSN: 2222-6990 @ 2019 HRMARS

Table 1. Summary of the reliability instrument scales

\begin{tabular}{|l|c|}
\hline \multicolumn{1}{|c|}{ Constructs } & Cronbach's $\alpha$ \\
\hline Effort Expectancy (EE) & 0.843 \\
\hline Performance Expectancy (PE) & 0.931 \\
\hline Social Influence (SI) & 0.667 \\
\hline Perceived Playfulness (PP) & 0.938 \\
\hline Facilitating Conditions (FC) & 0.846 \\
\hline Attitude (ATT) & 0.806 \\
\hline Behavioral Intention (BI) & 0.921 \\
\hline Usage Behavior (UB) & 0.746 \\
\hline
\end{tabular}

\section{The Measurement Model}

The initial measurement model was conducted in AMOS software using the final list of indicators for the structural equation modeling (SEM) analysis. The UTAUT constructs were modeled as latent variables corresponding indicators as proposed in the base UTAUT model while covariances between latent variables were drawn. The initial measurement model was estimated using maximum likelihood estimation.

Table 2 summarizes the results of composite reliability (CR) and convergent validity (average variance extracted - AVE). To establish, the minimum value of $C R$ at 0.6 and 0.5 for the AVE respectively (Zainudin, 2015). CRs for the constructs in the final measurement model were between 0.698 and 0.940, and the estimated values for AVE were between 0.536 and 0.873 . Thus, the measurement model passed the convergent validity check. The diagonal value (in bold) is the square root of AVE of the construct while other values are the correlation between the respective constructs. The discriminant validity for all constructs is supported when the diagonal bold value was bigger than the correlation between variables (Fornell \& Larcker, 1981). The results of the tests for undimensionality, reliability, and convergent as well as discriminant validity provided evidence of the internal and external validity of the measurement instrument and scales.

Table 2. Measurement model validation

\begin{tabular}{ccccccccccc}
\hline & CR & AVE & \multicolumn{9}{c}{ Correlations (discriminant validity) } \\
& $>0.6$ & $>0.5$ & EE & PE & SI & PP & FC & ATT & BI & UB \\
\hline EE & 0.901 & 0.618 & $\mathbf{0 . 7 8 6}$ & & & & & & & \\
PE & 0.922 & 0.667 & 0.733 & $\mathbf{0 . 8 1 7}$ & & & & & & \\
SI & 0.698 & 0.536 & 0.510 & 0.643 & $\mathbf{0 . 7 3 2}$ & & & & & \\
PP & 0.940 & 0.725 & 0.751 & 0.805 & 0.588 & $\mathbf{0 . 8 5 1}$ & & & & \\
FC & 0.853 & 0.662 & 0.382 & 0.265 & 0.316 & 0.319 & $\mathbf{0 . 8 1 4}$ & & & \\
ATT & 0.914 & 0.598 & 0.676 & 0.761 & 0.587 & 0.781 & 0.407 & $\mathbf{0 . 7 7 3}$ & & \\
BI & 0.909 & 0.715 & 0.677 & 0.799 & 0.554 & 0.809 & 0.313 & 0.787 & $\mathbf{0 . 8 4 6}$ & \\
UB & 0.932 & 0.873 & 0.380 & 0.290 & 0.336 & 0.382 & 0.692 & 0.377 & 0.385 & $\mathbf{0 . 9 3 4}$ \\
\hline
\end{tabular}

$\mathrm{PE}=$ Performance Expectancy; $\mathrm{EE}=$ Effort Expectancy; $\mathrm{SI}=$ Social Influence; $\mathrm{PP}=$ Perceived Playfulness; $\mathrm{FC}=$ Facilitating Conditions; $\mathrm{ATT}=$ Attitude' $\mathrm{BI}=$ Behavior Intention; UB= Usage Behavior 
INTERNATIONAL JOURNAL OF ACADEMIC RESEARCH IN BUSINESS AND SOCIAL SCIENCES

Vol. 9, No. 13, Special Issue: Revolutionizing Education: Challenges, Innovation, Collaboration., 2019, E-ISSN: 2222-6990 @ 2019 HRMARS

\section{Structural Model}

The structural model was estimated after assessing the measurement model. The assessment of the final structural model was demonstrated a good fit of the models according to the fitness indexes as shown in Table 3.

Table 3. The fitness indexes for structural model

\begin{tabular}{|c|c|c|c|c|c|c|}
\hline Fit Index & $x^{2}$ & $\mathrm{df}$ & $\mathrm{x}^{2} / \mathrm{DF}$ & $\mathrm{CFI}$ & $\mathrm{RMSEA}$ & $\mathrm{NFI}$ \\
\hline Index Value & 985.983 & 445 & $2.216<3.00$ & $0.903>0.9$ & $0.078<0.08$ & $0.838>0.80$ \\
\hline
\end{tabular}

The final structural model (Figure 1$)$ show that $P E(\beta=0.426 ; p<0.001)$ and $P P(\beta=0.480 ; p<0.001)$ positively affect academicians' behavioral intention (BI) regarding the use of BL system in teaching. However, EE and SI have no significant relationship between the $B I$. $F C(\beta=0.733 ; p<0.001)$ positively affects the actual UB of BL system in teaching. The results of the structural model estimation also show that actual UB has been affected $(\beta=0.251 ; p<0.05)$ by $B I$ to use $B L$ system in teaching. However, the academician's in the actual UB of BL system is not affected by BI to use the BL system in teaching. The academician's attitude towards using the BL system in the future is affected by $P E(\beta=0.720$; $p<0.001)$ and $E E(\beta=0.235 ; p<0.01)$. The coefficient of determination $R^{2}$ indicates that $60.4 \%$ of the total variance of the user behavior on BL system in teaching can be explained by PE, EE, SI, PP, FC, $A T T$, and BI to use BL system in UTAUT model.

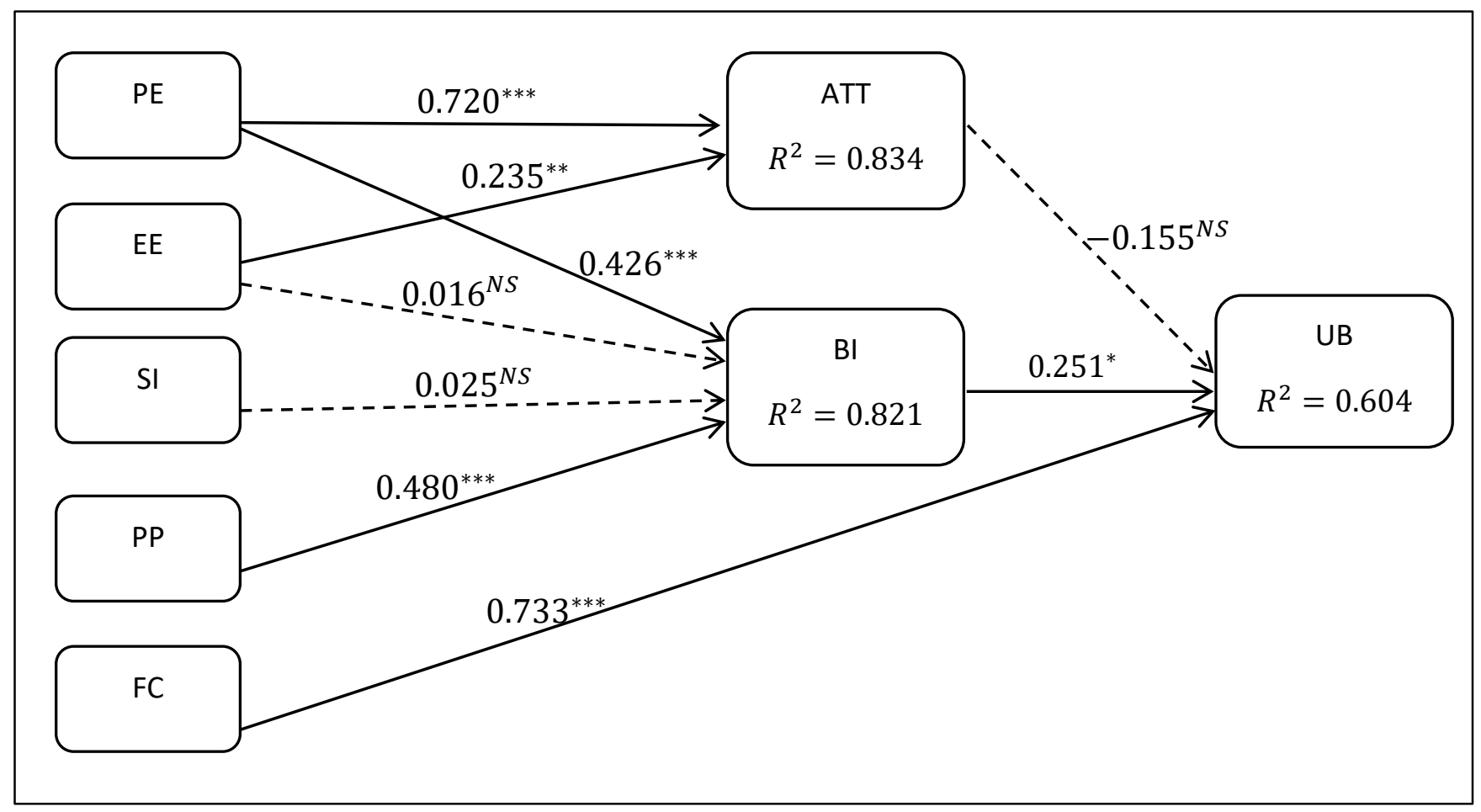

significant relation non-significant relation 
INTERNATIONAL JOURNAL OF ACADEMIC RESEARCH IN BUSINESS AND SOCIAL SCIENCES

Vol. 9, No. 13, Special Issue: Revolutionizing Education: Challenges, Innovation, Collaboration., 2019, E-ISSN: 2222-6990 @ 2019 HRMARS

$* * * \mathrm{p} \leq 0.001 * * \mathrm{p} \leq 0.01 * \mathrm{p} \leq 0.5$

$\mathrm{PE}=$ Performance Expectancy; $\mathrm{EE}=$ Effort Expectancy; $\mathrm{SI}=$ Social Influence; $\mathrm{PP}=$ Perceived Playfulness; $\mathrm{FC}=$ Facilitating Conditions; $\mathrm{ATT}=$ Attitude' $\mathrm{BI}=$ Behavior Intention; UB= Usage Behavior

Figure 1. Final structural model

\section{Hypotheses Testing}

In the hypothesis testing, moderating factors were proposed to analyze the significant differences in the causal effect sizes between different groups of cases. Individual groups were defined and sub-models for the defined groups were estimated. For factors such as gender, age, teaching experience, and user type, the distribution into appropriate groups was evident. Age and teaching experience have been separated as shown in Table 4.

Table 4. The summary of differences of causal effect sizes

\begin{tabular}{|l|l|l|l|}
\hline Factor & Demographic characteristics & New groups & Distribution \\
\hline \multirow{2}{*}{ Age } & Less than 45 & younger & $173(86.1 \%)$ \\
\cline { 2 - 4 } & 46 and above & older & $28(13.9 \%)$ \\
\hline \multirow{2}{*}{$\begin{array}{l}\text { Teaching } \\
\text { experience }\end{array}$} & Less than 5 years' experience & Early stage of teaching & $53(26.4 \%)$ \\
\cline { 2 - 4 } & More than 5 years' experience & experienced & $148(73.6 \%)$ \\
\hline
\end{tabular}

In order to identify the significance level of differences in causal effect sizes for the moderating factors, a multi-group analysis was conducted by using SEM model. The results of the multi-group analysis is demonstrated in Table 5, which indicate that the effect of PE on BI is significantly stronger for younger academicians. However, no significant differences have been estimated for the causal path $\mathrm{EE} \rightarrow \mathrm{BI}$ and $\mathrm{SI} \rightarrow \mathrm{BI}$. The effect of $\mathrm{PP}$ on $\mathrm{BI}$ has a significantly stronger effect on female and younger academicians with less than 5 years of teaching experiences. The FC also has a significantly stronger effect on female and younger lecturers with more than 5 years of teaching experienced. The PE has a significantly stronger effect on ATT for female and younger lecturers with more than 5 years of teaching experiences. However, the effect of EE on ATT has a significant effect on male and older teacher. The $\mathrm{BI}$ has a strong significant effect on younger academicians in the actual usage behavior of BL system in teaching. 
INTERNATIONAL JOURNAL OF ACADEMIC RESEARCH IN BUSINESS AND SOCIAL SCIENCES

Vol. 9, No. 13, Special Issue: Revolutionizing Education: Challenges, Innovation, Collaboration., 2019, E-ISSN: 2222-6990 @ 2019 HRMARS

Table 5. The summary of differences of causal effect sizes

\begin{tabular}{|l|l|l|l|l|}
\hline Path & Gender & Age & Teaching Exp. & User Type \\
\hline$P E \rightarrow B I$ & $0.033^{N S}$ & $0.382^{* * *}$ & $0.471^{N S}$ & $0.214^{N S}$ \\
\hline$E E \rightarrow B I$ & $0.160^{N S}$ & $0.003^{N S}$ & $-0.238^{N S}$ & $0.162^{N S}$ \\
\hline$S I \rightarrow B I$ & $0.009^{N S}$ & $0.007^{N S}$ & $0.063^{N S}$ & $0.155^{N S}$ \\
\hline$P P \rightarrow B I$ & $0.396^{* * *}$ & $0.419^{* * *}$ & $0.551^{* *}$ & $0.274^{N S}$ \\
\hline$F C \rightarrow U B$ & $0.821^{* * *}$ & $0.906^{* * *}$ & $0.701^{* * *}$ & $0.598^{* * *}$ \\
\hline$P E \rightarrow A T T$ & $0.381^{*}$ & $0.717^{* * *}$ & $0.657^{* * *}$ & $0.527^{* *}$ \\
\hline$E E \rightarrow A T T$ & $0.749^{* *}$ & $0.241^{* *}$ & $0.256^{N S}$ & $0.523^{* *}$ \\
\hline$B I \rightarrow U B$ & $0.819^{N S}$ & $0.396^{*}$ & $-0.081^{N S}$ & $0.344^{N S}$ \\
\hline$A T T \rightarrow U B$ & $-0.372^{N S}$ & $-0.298^{N S}$ & $0.222^{N S}$ & $0.307^{N S}$ \\
\hline
\end{tabular}

$\mathrm{PE}=$ Performance Expectancy; $\mathrm{EE}=\mathrm{Effort}$ Expectancy; $\mathrm{SI}=$ Social Influence; $\mathrm{PP}=$ Perceived Playfulness; $\mathrm{FC}=$ Facilitating Conditions; $\mathrm{ATT}=$ Attitude' $\mathrm{BI}=$ Behavior Intention; UB= Usage Behavior

\section{Discussion}

This study focused on the development and empirically validity of the extended UTAUT model by addressing the new variable, which are PP and ATT, along with the new moderators in order to identify the level of acceptances toward behavioral intentions (INT) and the actual usage behavior (UB) of BL system in teaching among academicians. Some of the objectives have been statistically verified. The new variable which are PP and ATT is related to BL system in teaching however, PP is more significant. The results are consistent with the findings in the previous studies (Moon and Kim, 2001; Sumak and Sorgo, 2016) which are positively and significantly related to behavior intention to use BL system in teaching.

With empirical validations and an estimation of the extended UTAUT model, the analysis in the perception of potential and actual academic users in BL system in teaching constitute the most important factors that influence the level of acceptance. Descriptive statistics have revealed that lecturers score higher for all indicators of UTAUT constructs. The multi-group SEM analysis show that there is a significant effect in several causal relationships, indicating the need to introduce a new moderating variable in the UTAUT model. This shows that it is in accordance with the literature on the hypothesis testing on the previous studies (Sumak and Sorgo, 2016; Venkatesh et al. 2003). These findings reveals that the effect on behavior intention to use BL system in teaching was significantly affected academicians. The following subsection discussed further implications and the limitations of the study.

\section{Implications for Research and Practice}

This study has produced some useful theoretical and practical implications. Theoretically, this study adapts the basic UTAUT model in the context of the BL system in teaching. It can be concluded that UTAUT can be used in studies that investigate the factors that influence the acceptance and use of educational technology in schools and universities. However, some modifications of the original UTAUT model need to be considered and used. In existing literature, there are several studies that have validated the UTAUT model in the context of the BL system in teaching, but for the best part of 
knowledge, this study is the first attempt to simultaneously and empirically validate the UTAUT research model using the responses from academicians in the educational technology acceptance, in the teaching and learning processes. The study published in existing literature has addressed, and has investigated the factors that influence the acceptance and use of certain educational technologies (Marques et al., Sumak \& Sorgo, 2016; Gawande, 2015; Ajide \& Tik, 2009). In the basic UTAUT model, Venkatesh et al., (2003) have proposed moderating variables such as gender, age, experience, and voluntariness.

In this study the significant effect in several paths indicates the factors and their impact on users' behavioral intentions (INT) and actual use (UB) of an educational technology that is significant among academicians in the BL system. Accordingly, the moderating variables introduce in this study is user type and teaching experiences. However, PP and ATT have also been added in this study as latent variables. All variables propose in this study is supplement the variables experience in using a certain technology from the base UTAUT model. The new latent variable in this study has been analyzed and the result has shown a significant effect in perceptions and causal relationship in the UTAUT model. The moderating variables propose in this study also show the significant effect in several factors between teachers and lecturers who possess more than 5 years of teaching experiences.

Practically, the findings provide evidence supporting the managerial implication and help design procedures for the successful introduction of educational technology in schools and universities, for academicians especially teachers and lecturers who are potential users although some academics have already used them. The moderating results in this study indicate that lecturers with more than 5 years of experiences in teaching for user type and teaching experience. Therefore, lecturers with experience in teaching demonstrate more understanding and acceptance of the $\mathrm{BL}$ system in teaching. Thus, the institution needs to provide training and exposure to academicians on the BL system. Meanwhile, authorities need to provide good facilities such as the efficient internet network in schools or universities.

Regarding the result from the model, the facilitating conditions show the most important construct in the acceptance of the BL system in teaching among academicians. Facilitating conditions show that academicians have BL system knowledge and the institutions (schools and universities) have supported the use of BL systemin teaching. Hence, the findings of this study provide the information to the institution that academicians are ready to used BL system. Therefore, academic institutions and academics should continue the efforts to develop BL systems to achieve their goals.

\section{Limitations and Future Directions}

This study has certain limitations that we should explained to make findings and to discuss opportunities for future research. First, the sampling method used in this study is a snowball sampling. Therefore, the results are probably biased in details and these trends are most probably not questionable. Thus, future research should be conducted using other sampling methods such as quota sampling of academicians.

Second, all the respondents in this study are a combinations of all academicians (teachers and lecturers). Correspondingly, future research is required to determine the generalizability of these results in relation to other populations, it is anticipated that other research will confirm this decision as academicians represent a major proportion of the people interested in the BL systemin teaching. 
INTERNATIONAL JOURNAL OF ACADEMIC RESEARCH IN BUSINESS AND SOCIAL SCIENCES

Vol. 9, No. 13, Special Issue: Revolutionizing Education: Challenges, Innovation, Collaboration., 2019, E-ISSN: 2222-6990 @ 2019 HRMARS

Therefore, to explore more details and understanding of the level of acceptance that impact the use of educational technology, focus groups should be considered.

\section{Conclusion}

Generally, from the point of view of its theoretical implications, this research provides results by incorporating moderating variables into the UTAUT model. This option offers evidence that it is possible to improve the performance of the model through a context of the dependent moderators. This study examines the new construct of PP, ATT, and the moderating effect of user type and teaching experience between BL systems. The findings suggest that lecturers with more than 5 years of experiences have the highest level in accepting the BL system. The results also provide evidence to show that the facilitating conditions and factors are more important in the acceptance of BL system among lecturers with more than 5 years of teaching experiences. Thus, the findings in this study hold implications for building $\mathrm{BL}$ system in teaching that are relevant to both practitioners and academicians.

\section{Acknowledgements}

The author, Nor Aslily binti Sarkam, gratefully acknowledges the financial aid from Majlis Amanah Rakyat (MARA) and his supervisor, Nobuhiko Terui for his great support and advice along the research process.

\section{References}

Appana, S. (2008). A review of benefits and limitations of online learning in the context of the student, the instructor and the tenured Faculty. International Journal on E-learning. 7(1), 5- 22.

Durndell, A., Thomson, K. (1997). Gender and computing: A decade of change?. Computer \& Education. 28(1), 1 - 9.

Fornell, C., Larcker, D. F. (1981). Evaluating structural equations models with unobservable variables and measurement error. Journal of Marketing Research. 18(1), $39-50$.

Gawande, V. (2015). Development of blended learning model based on the perceptions of students at higher education institutions in Oman. International Journal of Computer Applications. 114(1), $38-45$.

Hair, J., Black, W., Babin, B. Y. A., Anderson, R., Tatham, R. (1998). Multivariate Data Analysis, fifth ed. New Jersey: Pearson Prentice Hall.

Haron, H., Abbas, W. F., Rahman, N. A. A. (2012). The adoption of blended learning among Malaysian academicians. Procedia-Social and Behavioral Sciences. 67, 175 - 181.

Hubackova, S., Semradova, I., Klimova, B. F. (2011). Blended learning in foreign language teaching. Procedi-Social and Behavioral Sciences. 28, $281-285$.

Jones, S., Johnson-Yale, C., Millermaier, S., Perez, F. S. (2008). Academic work, the Internet and US college students. Internet and Higher Education. 11, 165 - 177.

Kim, C., Park, H. (2013). Effects of various characteristics of social commerce (s-commerce) on consumers' trust and trust performance. International Journal of Information Management. 33(2), $318-332$.

Kline, R. B. (1998). Principles and practice of structural equation modeling, first ed. New York: Guilford Press. 
Moon, J., Kim, Y. (2001). Extending the TAM for a world-wide-web context. Information and Management. 38(4), $217-230$.

Norberg, A., Dziuban, C. D., Moskal, P. D. (2011). A time-based blended learning model. On the Horizon. 19, $207-216$.

Nunnally, J. C. (1978). Psychometric Theory, second ed. New York: McGraw-Hill.

Osman, N. B., Hamzah, M. I. B. (2016). Hubungan kesediaan pelajar mengikuti pembelajaran berasaskan blended learning berdasarkan jantina dan program. Jurnal kukikulum \& Pengajaran Asia Pasifik. 4(2).

Radcliffe, D. (2002). Technological and pedagogical convergence between work-based and campusbased learning. Educational Technology \& Society. 5, $54-59$.

Sumak, B., Sorgo, A. (2016). The acceptance and use of interactive whiteboards among teachers: Differences in UTAUT determinants between pre-and post- adopters. Computers in Human Behavior. 64, $602-620$.

Venkatesh, V. (2000). Determinants of perceived ease of use: Integrating control, intrinsic motivation, and emotion into the technology acceptance model. Information Systems Research. 11(4), $342-365$.

Venkatesh, V., Bala, H. (2008). Technology acceptance model 3 and research agenda on interventions. Decision Sciences. 39(2), $273-315$.

Venkatesh, V., Davis, F. D. (2000). A theoretical extension of the technology acceptance model: Four longitudinal field studies. Management Science. 46(2), 186- 204.

Venkatesh, V., Morris, M. G., Ackerman, P. (2000). A longitudinal field investigation of gender differences in individual technology adoption decision making processes. Organizational Behavior and Human Decision Processes. 83(1), $33-60$.

Venkatesh, V., Morris, M. G., Davis, G. B., Davis, F. D. (2003). User acceptance of information technology: Toward a unified view. MIS Quarterly. 27(3), 425 -478.

Venkatesh, V., Thong, J. Y., Xu, X. (2012). Consumer acceptance and use of information technology: extending the unified theory of acceptance and use of technology. MIS quarterly. 36(1), 157 -178 .

Venkatesh, V., Morris, M., Davis, G., Davis, F., DeLone, W., McLean, E., Jarvis, C., MacKenzie, S., Podsakoff, P., Chin, W. (2003). User acceptance of information technology: Toward a unified view. Inform Management. 27, 425 - 478.

Wong, K-T., Russo, S., McDowall, J. (2012). Understanding early childhood student teachers' acceptance and use of interactive whiteboard. Campus-Wide Information System. 30(1), 4 16.

Zainudin, A. (2015). SEM made simple. MPWS Publisher. 